\title{
Balancing Potential Benefits and Risks of Bruton Tyrosine Kinase Inhibitor Therapies in Multiple Sclerosis During the COVID-19 Pandemic
}

Martin S. Weber, MD, * Jacqueline A. Nicholas, MD, MPH,* and Michael R. Yeaman, PhD

Neurol Neuroimmunol Neuroinflamm 2021;8:e1067. doi:10.1212/NXI.0000000000001067

\section{Abstract}

Bruton tyrosine kinase inhibitors (BTKis) encompass a new class of therapeutics currently being evaluated for the treatment of multiple sclerosis (MS). Whether BTKis affect COVID-19 risk or severity or reduce vaccine efficacy are important but unanswered questions. Here, we provide an overview on BTKi mechanisms relevant to COVID-19 infection and vaccination and review preliminary data on BTKi use in patients with COVID-19. BTKis block B-cell receptorand myeloid fragment crystallizable receptor-mediated signaling, thereby dampening B-cell activation, antibody class-switching, expansion, and cytokine production. Beyond antibodies, COVID-19 severity and vaccine efficacy appear largely linked to T-cell responses and interferon induction, processes not directly affected by BTKis. Given that B cells have clear roles in antigen presentation to $\mathrm{T}$ cells, however, it is possible that BTKis may indirectly interfere with beneficial or detrimental T-cell responses during COVID-19 infection or vaccination. In addition to these possible effects on generating a protective immune response, BTKis may attenuate the hyperinflammatory dysregulation often seen in severe cases of COVID-19 that evolves as a key risk factor in this disease. Currently available outcomes from BTKi-treated patients with COVID-19 are discussed. Clinical trials are currently underway to evaluate the safety and efficacy of BTKis in individuals with MS. Although limited data suggest a potential benefit of BTKis on outcomes for some COVID-19 patients, data from adequately powered, prospective and randomized clinical trials are lacking. Likewise, the specific effect of BTKis on the safety and efficacy of COVID-19 vaccines remains to be determined. Any potential unknown risks that BTKi therapy may present to the patient relative to COVID-19 infection, severity, and vaccine efficacy must be balanced with the importance of timely intervention to prevent or minimize MS progression.

\author{
Correspondence \\ Dr. Weber \\ martin.weber@ \\ med.uni-goettingen.de
}

\section{MORE ONLINE}

COVID-19 Resources

For the latest articles, invited commentaries, and blogs from physicians around the world NPub.org/COVID19

\footnotetext{
*These authors contributed equally to this work.

From the Institute of Neuropathology (M.S.W.), University Medical Center; Department of Neurology (M.S.W.), University Medical Center, Göttingen, Germany; OhioHealth Multiple Sclerosis Center (J.A.N.), Riverside Methodist Hospital, Columbus, OH; David Geffen School of Medicine (M.R.Y.), University of California, Los Angeles (UCLA); Divisions of Molecular Medicine and Infectious Diseases (M.R.Y.), Harbor-UCLA Medical Center; and Lundquist Institute for Biomedical Innovation at Harbor-UCLA Medical Center (M.R.Y.), Torrance, CA. 


\section{Glossary}

$\mathbf{B T K}=$ Bruton tyrosine kinase $\mathbf{B T K i}=$ Bruton tyrosine kinase inhibitor; $\mathbf{C L L}=$ chronic lymphocytic leukemia; $\mathbf{D M T}=$ diseasemodifying therapy; Fc = fragment crystallizable; IFN = interferon; IL = interleukin; MS = multiple sclerosis; SARS-CoV-2 = severe acute respiratory syndrome coronavirus 2; TLR = Toll-like receptor; XLA = X-linked agammaglobulinemia.

Multiple sclerosis (MS) is a chronic, inflammatory disease characterized by progressive demyelination and degeneration of the CNS that can lead to profound disability. ${ }^{1}$ Ongoing clinical studies of disease-modifying therapies (DMTs) are essential to address unmet needs in the treatment of MS. Unfortunately, the current COVID-19 pandemic has made enrollment in clinical trials and initiation of new therapies challenging for individuals with MS and health care professionals. In particular, Bruton tyrosine kinase inhibitors (BTKis) are a new therapeutic class currently being evaluated for efficacy to prevent relapses and/or chronic progression of MS. BTKis have a dual mechanism of action that targets aspects of both acute and chronic inflammation and thus may be of great benefit to people with either relapsing or primary progressive MS. ${ }^{2}$ Hesitancy to enroll in BTKi clinical trials may exist due to unfamiliarity with the new therapeutic mechanism and how this might influence COVID-19 susceptibility, severity, or vaccine response. In this review, we discuss emerging perspectives regarding BTKis with respect to COVID-19, with the goal of educating health care professionals on how to make more informed decisions with each individual patient affected by MS.

\section{BTKis in the Treatment of MS}

$\mathrm{B}$ and $\mathrm{T}$ lymphocytes play major roles in the MS inflammatory pathology. B cells are the source of antibody-producing plasma cells, provide both pro- and anti-inflammatory cytokines, and act as potent antigen-presenting cells in the activation and generation of $\mathrm{T}$ effector cells. ${ }^{3}$ Bruton tyrosine kinase (BTK) is an enzyme required for B-cell receptormediated signaling and activation of $\mathrm{B}$ cells and fragment crystallizable $(\mathrm{Fc})$ receptor signaling in myeloid lineage cells such as macrophages, monocytes, and neutrophils. ${ }^{4}$ BTKis are being evaluated as novel and attractive therapeutic options for MS because of their potential to control development of relapses and possibly mitigate disease progression. ${ }^{5}$ Currently, BTKis under investigation in patients with MS include evobrutinib (NCT04338022), tolebrutinib (NCT04410978, NCT04410991, NCT04411641, and NCT04458051), and fenebrutinib (NCT04586023, NCT04586010, and NCT04544449). Newer-generation BTKis appear to offer greater target selectivity, potentially reducing off-target effects compared with older BTKis. ${ }^{2}$

\section{BTK Signaling}

Early clues regarding the role of BTK in the immune system arose from studies of individuals with X-linked agammaglobulinemia (XLA), a disease in which BTK is mutated and nonfunctional. ${ }^{6}$ In this illness, the lack of normal BTK function results in severely reduced circulating B cells and immunoglobulins. ${ }^{6}$ It is now well established that BTK plays an essential role in B-cell activation, proliferation, and survival, as well as in signaling pathways of myeloid lineage cells. $^{4,7}$ In B cells, BTK is essential for B-cell receptor signaling and class switching, which in turn are required for antibody production, isotype diversity, and affinity maturation of humoral immunity. ${ }^{3,4}$ In the myeloid cell lineage, $\mathrm{BTK}$ regulates inflammatory signaling via $\mathrm{Fc}$ receptors and Toll-like receptors (TLRs). ${ }^{4}$

\section{Effect of BTKis on Antimicrobial Host Defense in General}

BTKis vary in their risk of infections. Over half of patients taking ibrutinib or acalabrutinib (first- and second- generation BTKis, respectively) experience an infectious event of any grade. ${ }^{8,9}$ These 2 BTKis have been associated with serious fungal infections such as aspergillosis in patients with cancer. $^{10,11}$ By comparison, later-generation BTKis such as fenebrutinib and evobrutinib show less frequent infectious events. Among fenebrutinib-treated individuals with rheumatoid arthritis, $8 \%-15 \%$ of patients had any infection. ${ }^{12}$ Among evobrutinib-treated individuals with MS, $19 \%-33 \%$ of patients had any infection. ${ }^{13}$ This pattern of results may be due to pharmacologic differences that allow for later generation BTKis to have greater target selectivity. ${ }^{2,14}$ In addition, much of the data regarding general infections with BTKis are from studies of individuals with malignancies, who may have higher risks of infection even in the absence of therapy. Nonetheless, it should be recognized that, by their mechanism of action, all BTKis have at least a theoretical risk of raising vulnerability to infection.

\section{COVID-19 Pathogenesis and Risk of Severe Infection}

COVID-19 is driven by the novel severe acute respiratory syndrome coronavirus 2 (SARS-CoV-2), a nonretroviral RNA virus that binds to angiotensin-converting enzyme 2 on airway epithelium and other tissues where these receptors are most abundant. ${ }^{15,16}$ SARS-CoV-2 infection triggers innate immune responses that are largely evoked by recognition of viral RNA via TLRs, prompting interferon (IFN) induction and macrophage activation. ${ }^{15}$ SARS-CoV-2 infection also triggers adaptive immune responses including B-cell activation, leading to generation of neutralizing antibodies and robust $\mathrm{CD} 4^{+}$ 
T-cell responses that, in turn, govern activation of $\mathrm{CD} 8^{+}$ $\mathrm{T}$ cell-mediated immunity. ${ }^{17-19}$ However, in COVID-19 infections, these immune responses can also become aberrant, increasing the risk for severe outcomes.

If early immune responses fail to control the infection (e.g., viral-specific T cells and IFN production), ${ }^{20}$ a profound expression of proinflammatory cytokines from injured lung tissue and immune cells can ensue (e.g., hyperinflammatory syndrome, often termed "cytokine storm"). ${ }^{15,21}$ This uncontrolled inflammatory signaling triggers massive monocyte, neutrophil, and macrophage infiltration into the lungs, corresponding with edema and diminished oxygenation. ${ }^{15,16}$ The hyperinflammatory milieu leads to severe acute respiratory distress often requiring mechanical ventilation, and pulmonary or multiorgan failure is the main cause of mortality. ${ }^{15,16}$ In addition, patients with COVID-19 frequently present with lymphopenia, particularly reduced $\mathrm{CD} 4^{+}$and $\mathrm{CD} 8^{+} \mathrm{T}$ cells, that often correlates with greater disease severity (Table 1$){ }^{22}$ Severe cases of COVID-19 also exhibit $\mathrm{CD}^{+}$and $\mathrm{CD} 8^{+}$ T-cell functional exhaustion, reduced IFN $\gamma$ response, ${ }^{23,24}$ and higher levels of interleukin (IL)-6, virus-specific antibodies, and neutrophils compared with mild or moderate cases. ${ }^{21,24}$ Individuals recovering from COVID-19 have $\mathrm{CD}^{+}$and $\mathrm{CD}^{+} \mathrm{T}$ cells that primarily produce IFN $\gamma,{ }^{25}$ as well as increases in circulating $\mathrm{T}$ follicular helper cells, suggesting that these factors may be biomarkers of a protective or convalescent immune response. ${ }^{19,25}$

The prevailing evidence to date suggests that the key risk factors for developing severe COVID-19 disease are demographics (e.g., older age, socioeconomic status, and race/ ethnicity factors) and certain comorbidities such as hypertension, diabetes, and obesity. ${ }^{16,26}$ MS does not appear to be an independent risk factor for COVID-19 infection or disease severity. ${ }^{27,28}$ However, the effect of DMTs that attenuate B- and T-cell responses is not well understood at present and could in theory blunt protective immunity against COVID-19 disease.

\section{BTKi Mechanisms of Action and COVID-19 Pathology}

Identifying parallels between known BTKi mechanisms of action and current knowledge about COVID-19 pathogenesis may be helpful in supporting clinical decision making during the COVID-19 pandemic. Given that knowledge regarding COVID-19 pathology is limited and evolving rapidly, the following information is provided solely to inform the reader on general themes at present, without specific recommendations based on this knowledge.

\section{Viral Clearance}

T cells are crucial to controlling and clearing viral infections. ${ }^{29}$ As reviewed above and in Table 1, mounting evidence suggests that T-cell dynamics may be central to clearance of COVID-19 infections. Existing data do not show any direct overlap of T cells with BTKi mechanisms in COVID-19 pathology. T cells generally show very low levels of BTK expression; accordingly, individuals with XLA who lack BTK have normal T-cell counts and function. ${ }^{30}$ However, because $\mathrm{B}$ and $\mathrm{T}$ cells engage in bidirectional modulation, BTKis may indirectly influence T cell-mediated responses. For example, $\mathrm{B}$ cells serve an important antigen-presenting role for $\mathrm{T}$ cells and generate significant levels of IL-6 and other cytokines that influence T-cell response and polarization (Figure 1). ${ }^{31}$ Thus, it is plausible that interruption of B-cell activation by BTKis could attenuate either beneficial or detrimental T-cell responses in COVID-19.

Positive seroconversion to SARS-CoV-2-specific antibodies is another component of the immune response to COVID-19 infection. BTKis reduce circulating antibodies by inhibiting B-cell activation, which is required for the development of antibody-producing plasmablasts and memory B cells. ${ }^{32}$ Notably, however, the highest levels of neutralizing antibodies may be found in patients with the most severe cases of COVID-19, ${ }^{33,34}$ indicating that antibody responses alone may not be sufficient to clear the virus or allow for recovery from COVID-19 infection. Finally, it is plausible that BTKis may attenuate the ability of myeloid cells to function in antigen presentation to $\mathrm{T}$ cells, ${ }^{7,35}$ which could affect $\mathrm{T}$-cell activation. Whether the overall effect of such interference on viral clearance or hyperinflammatory syndrome would be beneficial or detrimental is unknown.

\section{Hyperinflammatory Syndrome}

The hyperinflammatory response in COVID-19 shares biological characteristics with macrophage activation syndrome, an immunologic process for which BTK is required. ${ }^{36}$ BTK plays an active role in the polarization of macrophages to a proinflammatory phenotype by regulating transcription factors such as nuclear factor- $\mathrm{\kappa B}$ (Figure 2). ${ }^{37}$ By blocking TLRdependent nuclear factor- $\kappa B$ activation in macrophages, BTKis dampen cytokine production from these cells. ${ }^{38}$ During severe COVID-19, the heightened levels of IL- $1 \beta$ indicate the development of NLRP3 inflammasomes, which may drive disease severity. ${ }^{39}$ BTKis can attenuate such inflammasomemediated IL- $1 \beta$ production. ${ }^{40}$ BTK is also required for leukocyte migration to the infection site ${ }^{41}$; thus, BTKis may attenuate the influx of neutrophils to the lungs during hyperinflammatory syndrome of COVID-19. An observational trial is currently investigating the association of BTK and hyperinflammation in COVID-19 (RESPOND; NCT04394884). This trial will evaluate hospitalized patients with COVID-19 who receive a BTKi as a COVID-19 treatment. Analysis of inflammatory pathways will be performed before and after BTKi treatment to understand the mechanism by which BTKis may attenuate hyperinflammation in COVID-19. 
Table 1 Blood Lymphocyte Findings in the Context of COVID-19 Infection

\begin{tabular}{|c|c|c|}
\hline Reference & Population & Findings \\
\hline $\begin{array}{l}\text { Xu B, Fan CY, Wang AL, et al. J Infect } \\
\text { 2020;81:e51-e60. }\end{array}$ & $\begin{array}{l}\text { - } 187 \text { hospitalized patients with } \\
\text { COVID-19 }\end{array}$ & $\begin{array}{l}\text { - } \mathrm{CD}^{+} \mathrm{T} \text { cells, } \mathrm{CD} 4^{+} \mathrm{T} \text { cells, } \mathrm{CD} 8^{+} \mathrm{T} \text { cells, and NK cells reduced to } \approx 50 \% \text { of normal } \\
\text { values } \\
\text { - Patients with lower lymphocyte levels had a greater risk of death } \\
\text { - "Warning" values predictive of death were observed: } \\
\bigcirc \text { Total lymphocytes: } 559 \text { cells/ } \mu \mathrm{L} \\
\bigcirc \mathrm{CD}^{+} \mathrm{T} \text { cells: } 235 \text { cells } / \mu \mathrm{L} \\
\bigcirc \mathrm{CD} 4^{+} \mathrm{T} \text { cells: } 104 \text { cells } / \mu \mathrm{L} \\
\bigcirc \mathrm{CD} 8^{+} \text {T cells: } 85 \text { cells } / \mu \mathrm{L} \\
\text { O B cells: } 82 \text { cells } / \mu \mathrm{L}\end{array}$ \\
\hline
\end{tabular}

\begin{tabular}{|c|c|c|}
\hline $\begin{array}{l}\text { Liao M, Liu Y, Yuan J, et al. Nat Med } \\
\text { 2020;26:842-844. }\end{array}$ & $\begin{array}{l}\text { - } 13 \text { patients with COVID-19 ( } 3 \\
\text { moderate, } 2 \text { severe, and } 8 \text { critical) }\end{array}$ & $\begin{array}{l}\text { - Patients with severe and critical infections had lower } \mathrm{CD} 8^{+} \mathrm{T} \text { cells and greater } \\
\text { proliferating T-cell proportions compared with patients who had moderate } \\
\text { infections }\end{array}$ \\
\hline $\begin{array}{l}\text { Diao B, Wang C, Tan Y, et al. Front } \\
\text { Immunol 2020;11:827. }\end{array}$ & $\begin{array}{l}\text { - } 522 \text { patients with laboratory- } \\
\text { confirmed COVID-19 } \\
\text { - } 40 \text { healthy controls }\end{array}$ & $\begin{array}{l}\text { - Patients who developed severe or critical disease and those who died had } \\
\text { significant reductions in total T cells, CD4 }{ }^{+} T \text { cells, and } C D 8^{+} T \text { cells compared with } \\
\text { patients who developed mild to moderate disease } \\
\text { - Total T cells, CD4 } 4^{+} \text {cells, and CD8 }{ }^{+} T \text { cells were significantly lower in patients } \\
\text { requiring ICU admission vs non-ICU patients } \\
\text { - Compared with healthy controls, patients with COVID-19 had significantly } \\
\text { higher levels of PD-1 expression on T cells; greater increases were associated } \\
\text { with more severe disease }\end{array}$ \\
\hline
\end{tabular}

Zheng C, Kar I, Chen CK, et al. CNS • 16 patients with COVID-19 (10 • Severe disease was associated with lower expression of IFNy and tumor Drugs 2020;34:879-896. mild and 6 severe) necrosis factor-a in $\mathrm{CD} 4{ }^{+} \mathrm{T}$ cells vs mild disease - Severe disease had greater frequency of exhaustion markers (PD-1, CTLA-4, and TGIT) in CD8 ${ }^{+} \mathrm{T}$ cells vs patients with mild disease or healthy controls

Sekine T, Perez-Potti A, Rivera- $\quad$ • 206 patients with COVID-19 Ballesteros O, et al. Cell

- $\mathrm{CD} 4^{+} \mathrm{T}$ cells and $\mathrm{CD} 8^{+} \mathrm{T}$ cells were very low in patients with moderate to severe 2020;183:158-168.e14. disease, with greater PD-1 expression ${ }^{\mathrm{a}}$; $\mathrm{CD}^{+} \mathrm{T}$ cells showed extremely high expression of activation marker $\mathrm{CD} 38^{+}$ - $\mathrm{CD} 4^{+} \mathrm{T}$ cells were skewed toward a circulating Tfh phenotype in recovered patients

- Appearance of stem-like memory T cells was associated with recovery - More recovering patients showed memory T-cell responses without antibody responses vs those who showed both

\begin{tabular}{ll}
\hline Weiskopf D, Schmitz KS, Raadsen & $\bullet 10$ patients with COVID-19 \\
MP, et al. Sci Immunol 2020;5(48). & admitted to the ICU \\
& $\begin{array}{ll}\bullet & 10 \text { healthy controls }\end{array}$
\end{tabular}

June JA, Han HX, Lee WS, et al. Nat • 41 patients who recovered from Med 2020;26:1428-1434. COVID-19 - 27 healthy controls
- Patients with COVID-19 had reduced $\mathrm{CD}^{+} \mathrm{T}$ cells and an increased $\mathrm{CD} 4^{+}: \mathrm{CD}^{+}$ ratio in the peripheral blood compared with healthy controls - SARS-CoV-2-specific CD4 ${ }^{+} \mathrm{T}$ cells were typically a central memory phenotype whereas $\mathrm{CD}^{+} \mathrm{T}$ cells tended to be the effector phenotype

- After infection resolved, patients consistently showed S-specific antibodies, memory B cells, and circulating Tfh cells

\section{Peng Y, Mentzer A, Liu G, et al. Nat • 42 patients who recovered from Immunol 2020;21:1336-1345. COVID-19 (28 mild and 14 severe) - 16 healthy controls}

- Broad, strong SARS-CoV-2-specific CD4 ${ }^{+}$and $\mathrm{CD}^{+}{ }^{+}$-cell responses were observed in the majority of recovering patients

- There was a greater $\mathrm{CD}^{+} \mathrm{T}$-cell response vs $\mathrm{CD} 4^{+} \mathrm{T}$-cell response in patients with mild disease

Mazzoni A, Salvati L, Maggi L, et al. $\cdot 30$ patients with COVID-19 J Clin Invest 2020;130:4694-4703. • 30 healthy controls

- Compared with healthy controls, patients with COVID-19 demonstrated

Increased neutrophils

Reduced cytotoxic T cells

$O$ Increased senescent cytotoxic T cells (indicating exhaustion)

Reduced T cells, B cells, and NK cells

- More pronounced increases in neutrophils and reductions in lymphocytes were observed in patients admitted to the ICU vs non-ICU patients

\begin{tabular}{ll}
\hline Hadjadj J, Yatim N, Barnabei L, & $\bullet 50$ patients with COVID-19 (mild to \\
et al. Science. 2020;369:718-724. & severe) \\
& $\bullet 18$ healthy controls
\end{tabular}

- Expression level of PD-1 on CD4 ${ }^{+} \mathrm{T}$ cells and $\mathrm{CD} 8^{+} \mathrm{T}$ cells was associated with disease severity

- High IFN response in mild to moderate cases, diminished in severe cases; low type I IFN observed before clinical worsening

Abbreviations: COVID-19 = coronavirus disease 2019; CTLA-4 = cytotoxic T-lymphocyte associated 4; ICU = intensive care unit; IFN = interferon; NK = natural killer; PD-1 = programmed death 1; SARS-CoV-2 = severe acute respiratory syndrome coronavirus 2; Tfh = T follicular helper; TIGIT = T-cell immunoglobulin and ITIM domain.

a PD-1 was interpreted as an activation marker (along with multiple inhibitory receptors) in this study, whereas other studies. ${ }^{23}$ interpreted it as an exhaustion marker. 


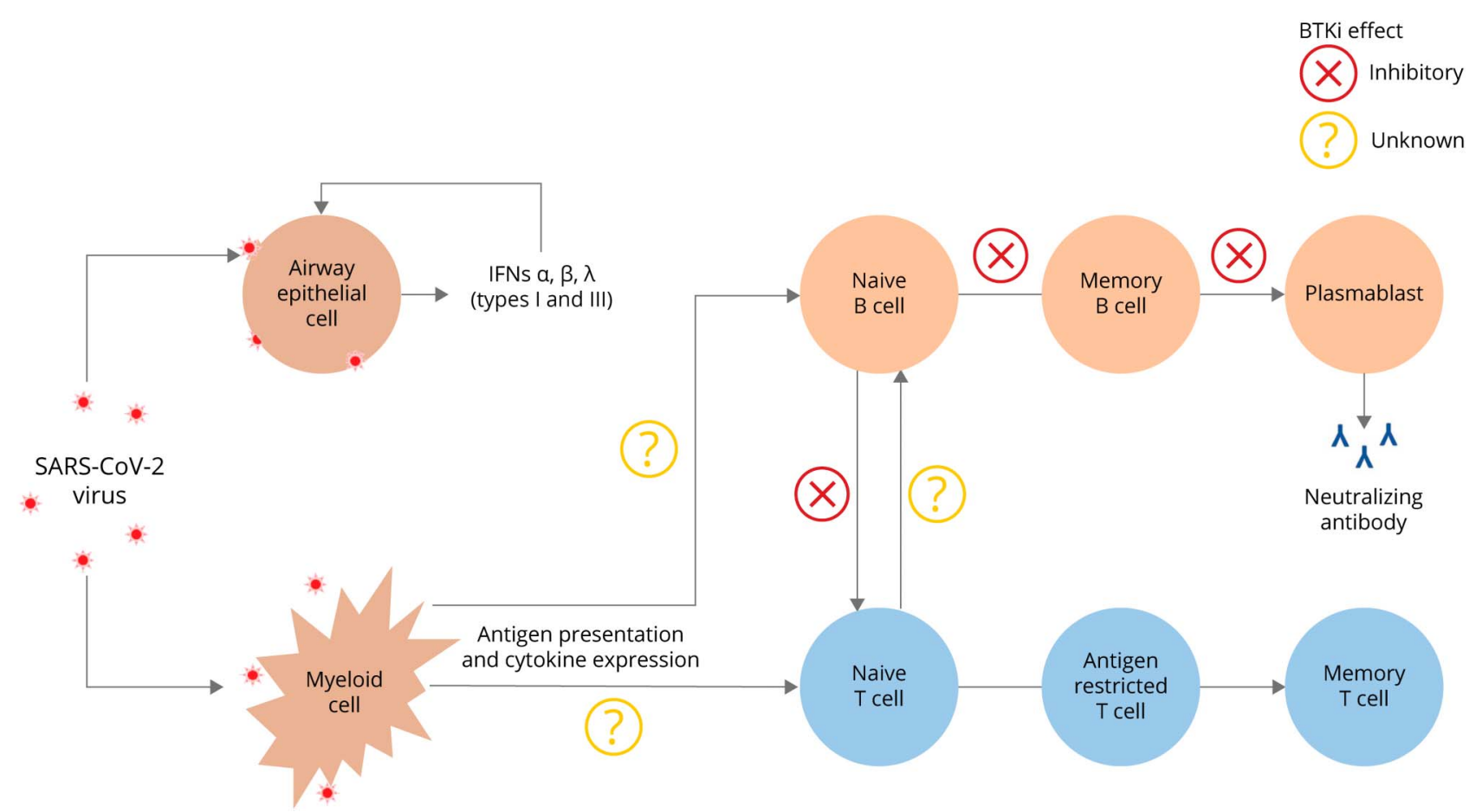

Early SARS-CoV-2 infection predominantly targets airway epithelial cells. Myeloid cells, including antigen-presenting cells, respond early in the course of infection, conditioning downstream responses of lymphocytes. Inhibition of BTK may affect multiple points of the immune response. BTKis prevent the development of naive B cells to memory B cells or plasmablasts, which are required for antibody generation. Antigen presentation and cytokine signaling among myeloid cells, B cells, and T cells may be altered or inhibited by BTK. BTK = Bruton tyrosine kinase; BTKi = Bruton tyrosine kinase inhibitor; IFN = interferon; SARS-CoV-2 = severe acute respiratory syndrome coronavirus 2.

\section{Evidence of the Effect of BTKis on COVID-19 Risk}

\section{Preclinical Evidence}

Data are limited regarding whether BTKis might increase susceptibility to or modify clearance in COVID-19 infection. Some anecdotal evidence suggests that BTKis might be protective against lung injury and hyperinflammation associated with COVID-19. For example, studies in mice have shown that BTKis may have therapeutic benefit in viral infections such as Epstein-Barr, HIV, and influenza A, as well as bacteremia or pulmonary infections. ${ }^{42-44}$ Such benefit may be due to blunting of cytokine responses to microbial components associated with sepsis (e.g., lipopolysaccharides), rather than promotion of the clearance of the pathogens themselves. ${ }^{42}$ In mice experimentally infected with influenza A virus, blocking BTK with ibrutinib increases survival, reverses weight loss, and reduces inflammation-associated tissue changes in the lungs. ${ }^{44}$

\section{Clinical Evidence}

Studies reporting COVID-19 outcomes in BTKi-treated patients are summarized in Table 2. Overall, these studies indicate potential benefit or no effect on COVID-19 outcomes from ibrutinib, acalabrutinib, or zanubrutinib. Promising results from a small study of individuals treated with acalabrutinib for COVID- $19^{45}$ prompted its formal assessment as a specific therapy for COVID-19 in the CALAVI clinical trials (NCT04380688 and NCT04346199). Unfortunately, these trials failed to meet their primary endpoints, as acalabrutinib did not increase the number of patients remaining alive and free from respiratory failure. ${ }^{46}$ Other BTKis are also being assessed in clinical trials as potential treatments for COVID-19 (Table 3).

On its surface, it may seem counterintuitive that BTKis, which inhibit B-cell activation and antibody production, could potentially be beneficial in COVID-19. However, several clinical observations provide plausibility for this concept. First, reports of individuals with XLA who contract COVID-19 do not indicate that they have any greater risk of severe outcomes than individuals with normal B-cell function. ${ }^{47,48}$ Second, COVID-19 convalescent plasma treatment, which contains a rich source of virus-specific antibodies, does not reduce mortality in patients with COVID-19 whose infections were advanced to the point of requiring mechanical ventilation. ${ }^{49}$ Third, patients with the most severe cases of COVID-19 often have the highest titers of specific antibodies. ${ }^{33,34}$ Collectively, these findings suggest that B-cell function and antibody generation may have secondary roles compared with $\mathrm{T}$ cells and IFNs in protective immunity against COVID-19. 


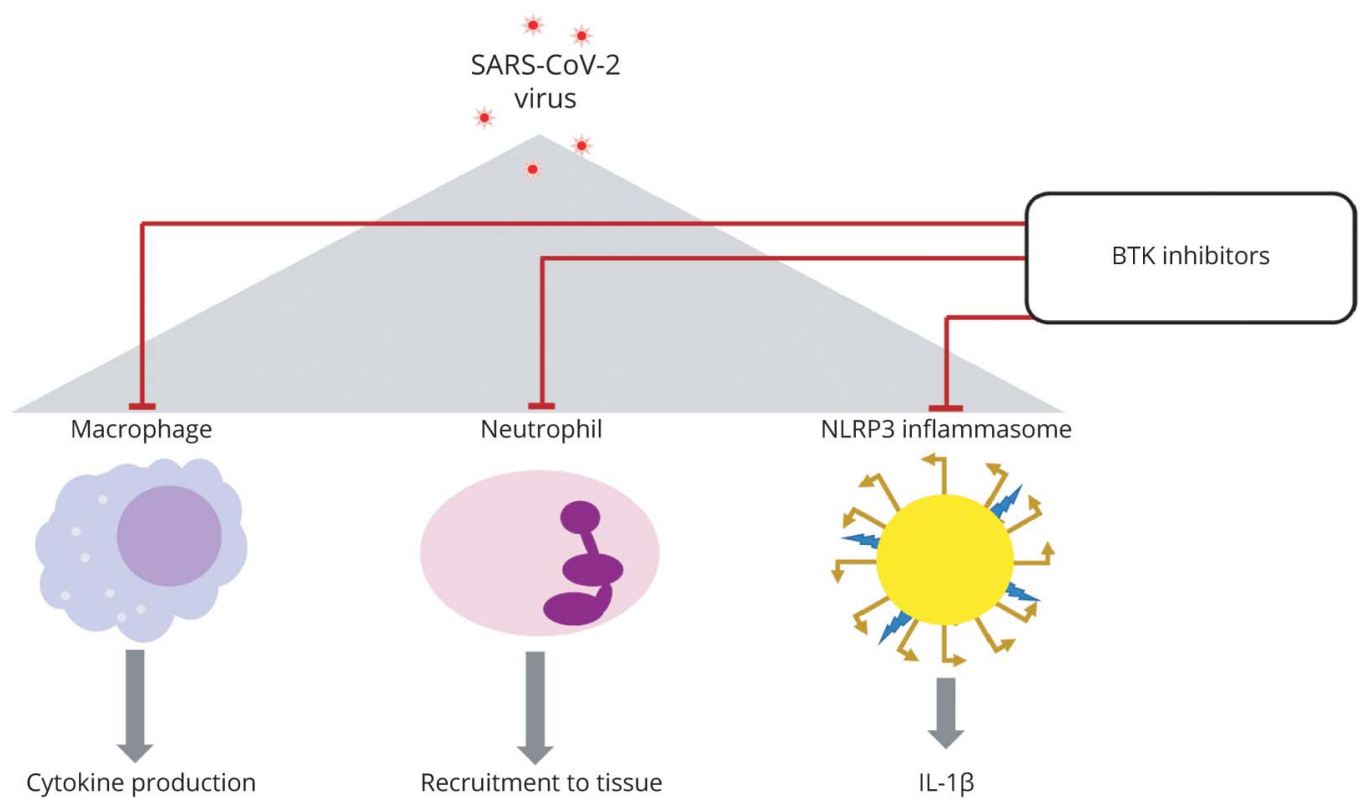

During COVID-19 hyperinflammation, which occurs in severe cases, infected airway epithelium and macrophages produce profusive amounts of cytokines, including those that chemoattract and activate granulocytes as well as Th1- and Th17-polarized T cells. In turn, neutrophils are recruited in massive quantities to the lungs, and the NLRP3 inflammasome becomes activated, increasing IL-1 $\beta$. The result of this successive cytokine storm and inflammatory infiltration is acute and chronic tissue damage of lungs, kidneys, and other target organs. BTKis may attenuate or inhibit all these hyperinflammatory aspects. BTKi = Bruton tyrosine kinase inhibitor; COVID-19, coronavirus disease 2019; IL = interleukin; SARS-CoV-2, severe acute respiratory syndrome coronavirus 2; Th, T helper cell.

Much caution should be exercised in interpreting the limited anecdotal information available. The pharmacologic differences of BTKis and context of disease treated (e.g., chronic lymphocytic leukemia [CLL] vs MS) must be considered when evaluating their potential effects in COVID-19, as BTKis can induce different off-target effects that could affect differential outcomes in COVID-19 infection. The patient populations demonstrating potential beneficial effects must be considered as well, as individuals with distinct comorbidities may experience nonidentical risks or benefits.

\section{Emerging Insights Regarding the Effect of BTKis on COVID-19 Vaccination}

Vaccines deliver protection by inducing innate and adaptive immune responses, involving $\mathrm{CD}^{+}$and $\mathrm{CD} 8^{+} \mathrm{T}$ cells, IFNs, $\mathrm{B}$ cells, and antibodies. ${ }^{50}$ Virus-specific neutralizing antibodies have generally been considered the primary components conferring vaccine-induced viral protection. In the case of SARS-CoV-2, concordant evidence (reviewed above) suggests that T-cell and IFN responses may be just as critical if not paramount in protection. ${ }^{51}$ Likewise, protection against severe outcomes in other SARS-CoV infections has also been associated with strong T-cell and IFN $\gamma$ responses. ${ }^{29,52}$ Furthermore, as discussed above, severe COVID-19 outcomes often occur despite high antibody titers, indicating that antibody development alone is insufficient to control or clear
SARS-CoV-2 infection. ${ }^{33,34}$ Collectively, these data suggest that COVID-19 vaccines that produce antigen-specific $\mathrm{T}$ cell-mediated immunity and IFNs, in addition to neutralizing antibodies, may yield the greatest protective efficacy. ${ }^{29,51,53}$

Several mRNA vaccines for COVID-19 have been developed that produce robust T-cell and IFN responses, in addition to SARSCoV-2-specific antibodies. Both the mRNA-1273 ${ }^{54}$ (Moderna/ $\mathrm{NIH})$ and BNT162b2 ${ }^{55}$ (Pfizer/BioNTech) vaccines induced expansion of $\mathrm{CD}^{+}$and $\mathrm{CD} 8^{+} \mathrm{T}$ cells skewed toward a T-helper 1 phenotype, and both vaccines elicited strong IFN $\gamma$ responses.

The response to COVID-19 vaccinations in patients treated with BTKis has not yet been studied. However, insights may be drawn from other vaccine responses in individuals taking BTKis and in those with XLA who are BTK-deficient. Most of the available data are from ibrutinib-treated patients with CLL; these data are sparse and have mixed outcomes. In a study of 19 such patients, $26 \%$ seroconverted to at least 1 strain of influenza following routine vaccination, ${ }^{56}$ but another study of 14 patients reported that only 1 individual seroconverted. ${ }^{57}$ In response to a pneumococcal conjugate vaccine, none of the 4 ibrutinib-treated patients mounted an adequate immune response (defined as $\geq 2$-fold increase in specific immunoglobulin $G$ titer), in contrast to all 4 of the untreated patients. ${ }^{58}$ Ibrutinib- or acalabrutinib-treated patients with CLL also exhibited an attenuated de novo serologic response to a recombinant hepatitis $\mathrm{B}$ vaccination compared with untreated patients. ${ }^{59}$ Of interest, in this same 
Table 2 Evidence of Possible Protective Effect of BTKis in COVID-19

\begin{tabular}{|c|c|c|c|}
\hline Reference & Population & Treatment & Outcome \\
\hline $\begin{array}{l}\text { Roschewski M, Lionakis MS, } \\
\text { Sharman JP, et al. Sci } \\
\text { Immunol 2020;5. }\end{array}$ & $\begin{array}{l}\text { - } 19 \text { patients with } \\
\text { COVID-19, } \\
\text { hospitalized for } \\
\text { hypoxemia }\end{array}$ & - Acalabrutinib (for COVID-19) & $\begin{array}{l}\text { - The majority of patients }(12 / 19) \text { had improved } \\
\text { oxygenation within } 1-3 \text { days of acalabrutinib initiation } \\
-4 \text { of } 8 \text { patients were removed from mechanical } \\
\text { ventilation } \\
\text { - } 2 \text { patients died }\end{array}$ \\
\hline $\begin{array}{l}\text { Treon S, Castillo J, Skarbnik } \\
\text { A, et al. Blood 2020;135:1912- } \\
\text { 1915. }\end{array}$ & $\begin{array}{l}\text { - } 6 \text { patients with } \\
\text { WM and COVID-19 }\end{array}$ & - Ibrutinib (for WM) & $\begin{array}{l}\text { - Patients receiving recommended dose }(420 \mathrm{mg} / \mathrm{d}) \\
\text { experienced no dyspnea and did not require } \\
\text { hospitalization } \\
\text { - } 1 \text { patient on a reduced dose }(140 \mathrm{mg} / \mathrm{d}) \text { experienced } \\
\text { progressive dyspnea and hypoxia requiring } \\
\text { hospitalization; the dose was increased after } 11 \text { days } \\
\text { to } 420 \mathrm{mg} / \mathrm{d} \text {, after which the patient experienced } \\
\text { rapidly increased oxygenation }\end{array}$ \\
\hline $\begin{array}{l}\text { Scarfo L, } \\
\text { Chatzikonstantinou T, } \\
\text { Rigolin G, et al. Leukemia } \\
\text { 2020;34:2354-2363. }\end{array}$ & $\begin{array}{l}\text { - } 190 \text { patients with } \\
\text { CLL and COVID-19 }\end{array}$ & $\begin{array}{l}\text { - BTKi (for CLL): } \\
\text { O Ibrutinib }(n=39) \\
\bigcirc \text { Acalabrutinib }(n=4) \\
\text { O Zanubrutinib }(n=1) \\
\text { - Other treatment for WM }(n=21) \\
\text { - } \text { Not currently treated }(n=125)\end{array}$ & $\begin{array}{l}\text { - The hospitalization rate for severe COVID- } 19 \text { was } \\
\text { lower in patients taking ibrutinib than patients taking } \\
\text { any other CLL therapies or no therapy (OR, } 0.44 ; 95 \% \\
\mathrm{Cl}, 0.20-0.96 ; p<0.05 \text { ) }\end{array}$ \\
\hline
\end{tabular}

Mato A, Roeker L, Lamanna • 198 patients with • BTKi monotherapy or combination therapy N, et al. Blood 2020;136:1134- CLL and COVID-19 (for CLL): 1143.

lbrutinib $(n=43)$
Acalabrutinib $(n=9)$

Zanubrutinib $(n=2)$

O lbrutinib + anti-CD20 ( $n=6)$

Acalabrutinib + anti-CD20 $(n=1)$

$O B T K i+$ venetoclax $(n=2)$

O BTKi + venetoclax + anti-CD20 $(n=1)$

$O B T K I+P I 3 K i+$ anti-CD2O $(n=3)$

O BTKi + fludarabine + pembrolizumab $(n=1)$

- Other treatment $(n=22)$

- Watch and wait $(n=108)$
- Similar survival in patients receiving BTKi treatment vs patients not receiving BTKi treatment at the time of COVID-19 diagnosis (HR, 0.73, 95\% $\mathrm{Cl}, 0.43-1.26$, $p=0.27)$

\author{
Lin A, Cuttica M, Ison M, \\ Gordon L. Eur J Haemotol \\ 2020; Sep 20:10.1002/ \\ jha2.98.

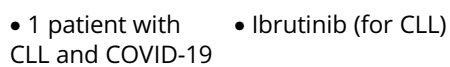

- 1 patient with • Ibrutinib (for CLL) 
the potential for vaccine responses to be impaired in context of higher doses of BTKi used for treating malignancies. It is plausible that lower doses, which may be used for treating autoimmune diseases, may not result in the same impairment.

Individuals lacking BTK activity due to XLA show different responses depending on the vaccine type. For example, tetanus vaccinations elicited similar responses in individuals with XLA compared with those without XLA. ${ }^{60}$ The response to H1N1 influenza vaccine is normal in both dendritic and $\mathrm{T}$ cells from individuals with XLA, as demonstrated by in vitro and in vivo studies. ${ }^{61,62}$ In response to polio vaccinations, however, dendritic cells from individuals with XLA show severely reduced type I and III IFN. ${ }^{62}$

Although it remains to be tested, BTKis are likely to attenuate direct B cell-mediated responses to COVID-19 vaccines, given that they reduce the proliferation, differentiation, and class switching required for antibody production. ${ }^{7}$

\section{Summary and Concluding Remarks}

MS remains an insidious and disabling disease, for which there is no cure to date. Individuals with MS do not appear to be at a higher risk of contracting COVID-19 or experiencing greater severity of COVID-19, due to having MS alone. BTKis are emerging as new therapeutic options for individuals with MS. The ability of BTKis to target inflammation via 2 routes, B-cell activation/ proliferation and myeloid-cell antigen-presentation/cytokine production, represents a novel mechanism for treating inflammation in MS that arises through both humoral- and cellmediated immunopathogenesis. BTKis do not directly affect $\mathrm{T}$ cells or IFN responses, which are immunologic factors that appear to be major drivers of COVID-19 host defense and resolution. However, BTKis may influence crosstalk between B and $\mathrm{T}$ cells, which could influence clearance of the SARS-CoV-2 virus or severity of disease outcomes. Limited evidence exists for COVID-19 disease outcomes in patients taking BTKis, and such evidence is mostly from individuals with cancer who may have altered immune functions. The potential effects of BTKis on COVID-19 vaccines have not yet been systematically studied.

One point remains certain: Early diagnosis and immediate treatment with an effective therapeutic regimen is strongly associated with better outcomes for individuals with MS. ${ }^{63}$ Delaying such treatment can have significant negative consequences to the long-term accumulation of irreversible disability. Increased exposure to COVID-19, advanced age, and certain comorbidities remain the primary risk factors for any individual to contract COVID-19. Careful consideration of these factors, along with status of disease progression and treatment goals, may be helpful to minimize individual risk of COVID-19. In all cases, the possible risks of COVID-19 should be weighed against the risk of serious complications from MS when considering any treatment or vaccination. Finally, although COVID-19 may be monopolizing the attention of medical professionals everywhere at this time, efforts to find new and improved therapeutic solutions that offer enhanced quality of life for individuals living with MS remain tremendously important even amidst the pandemic.

\section{Study Funding}

Editorial support (including assistance with drafting the manuscript for nonintellectual content, figure redraws, and copyediting) was provided by Emily Bruggeman, $\mathrm{PhD}$, of Health Interactions, Inc., and funded by Genentech, Inc., South San Francisco, CA.

\section{Disclosure}

M.S. Weber receives research support from the Deutsche Forschungsgemeinschaft (DFG; WE3547/5-1), Novartis, Teva, Biogen Idec, Roche, Merck, and the ProFutura Programm of the Universitätsmedizin Göttingen; serves as an Editor for PLoS One; and has received travel funding and/or speaker honoraria from Biogen Idec, Merck Serono, Novartis, Roche, Teva, Bayer, and Genzyme. J.A. Nicholas receives research funding from Biogen Idec, Novartis, ADAMAS, PCORI, and Alexion. She has received consulting fees from Alexion, Biogen, Novartis, Genentech, Bristol Myers Squibb, EMD Serono, Viela Bio, GW Pharmaceuticals, and John Hopkins CME. She has received speaking fees from Alexion, EMD Serono, Bristol Myers Squibb, Novartis, and Genentech. M.R. Yeaman is founder and a shareholder of NovaDigm Therapeutics, Inc., Tegos Therapeutics, Inc., and Metacin, Inc. He receives funding from the US NIH and US Department of Defense; holds multiple US and international patents on immunotherapeutic and anti-infective technologies; and is a member of the Genentech-Roche Scientific Advisory Committee and an adviser to The Guthy-Jackson Charitable Foundation. Go to Neurology.org/NN for full disclosures.

\section{Publication History}

Received by Neurology: Neuroimmunology \& Neuroinflammation May 4, 2021. Accepted in final form July 15, 2021.

Appendix Authors

\begin{tabular}{|c|c|c|}
\hline Name & Location & Contribution \\
\hline $\begin{array}{l}\text { Martin S. } \\
\text { Weber, MD }\end{array}$ & $\begin{array}{l}\text { University Medical } \\
\text { Center, Göttingen, } \\
\text { Germany }\end{array}$ & $\begin{array}{l}\text { Drafting/revision of the } \\
\text { manuscript for content, including } \\
\text { medical writing for content; major } \\
\text { role in the acquisition of data; } \\
\text { study concept or design; and } \\
\text { analysis or interpretation of data }\end{array}$ \\
\hline $\begin{array}{l}\text { Jacqueline A. } \\
\text { Nicholas, MD, } \\
\text { MPH }\end{array}$ & $\begin{array}{l}\text { Riverside Methodist } \\
\text { Hospital, Columbus, } \\
\mathrm{OH}\end{array}$ & $\begin{array}{l}\text { Drafting/revision of the } \\
\text { manuscript for content, including } \\
\text { medical writing for content; major } \\
\text { role in the acquisition of data; } \\
\text { study concept or design; and } \\
\text { analysis or interpretation of data }\end{array}$ \\
\hline $\begin{array}{l}\text { Michael R. } \\
\text { Yeaman, PhD }\end{array}$ & $\begin{array}{l}\text { University of } \\
\text { California, Los } \\
\text { Angeles (UCLA) }\end{array}$ & $\begin{array}{l}\text { Drafting/revision of the } \\
\text { manuscript for content, including } \\
\text { medical writing for content; major } \\
\text { role in the acquisition of data; } \\
\text { study concept or design; and } \\
\text { analysis or interpretation of data }\end{array}$ \\
\hline
\end{tabular}




\section{References}

1. Filippi M, Bar-Or A, Piehl F, et al. Multiple sclerosis. Nat Rev Dis Primers. 2018;4(1): 43.

2. Crawford JJ, Johnson AR, Misner DL, et al. Discovery of GDC-0853: a potent, selective, and noncovalent Bruton's tyrosine kinase inhibitor in early clinical development. J Med Chem. 2018;61(6):2227-2245.

3. Weber MS, Hemmer B. Cooperation of B cells and T cells in the pathogenesis of multiple sclerosis. Results Probl Cell Differ. 2010;51:115-126.

4. Rip J, Van Der Ploeg EK, Hendriks RW, Corneth OBJ. The role of Bruton's tyrosine kinase in immune cell signaling and systemic autoimmunity. Crit Rev Immunol. 2018; 38(1):17-62.

5. Torke S, Weber MS. Inhibition of Bruton s tyrosine kinase as a novel therapeutic approach in multiple sclerosis. Expert Opin Investig Drug. 2020;29(10):1143-1150.

6. Suri D, Rawat A, Singh S. X-linked agammaglobulinemia. Indian J Pediatr. 2016;83(4) 331-337.

7. Brunner C, Muller B, Wirth T. Bruton's Tyrosine kinase is involved in innate and adaptive immunity. Histol Histopathol. 2005;20(3):945-955.

8. Lipsky A, Lamanna N. Managing toxicities of Bruton tyrosine kinase inhibitors. Hematology. 2020;2020(1):336-345

9. Tillman BF, Pauff JM, Satyanarayana G, Talbott M, Warner JL. Systematic review of infectious events with the Bruton tyrosine kinase inhibitor ibrutinib in the treatment of hematologic malignancies. Eur J Haematol. 2018;100(4):325-334.

10. Alkharabsheh $\mathrm{O}$, Alsayed A, Morlote DM, Mehta A. Cerebral invasive aspergillosis in a case of chronic lymphocytic leukemia with Bruton tyrosine kinase inhibitor. Curr Oncol. 2021;28(1):837-841.

11. Varughese $\mathrm{T}$, Taur $\mathrm{Y}$, Cohen $\mathrm{N}$, et al. Serious infections in patients receiving ibrutinib for treatment of lymphoid cancer. Clin Infect Dis. 2018;67(5):687-692.

12. Cohen S, Tuckwell K, Katsumoto TR, et al. Fenebrutinib versus placebo or adalimumab in rheumatoid arthritis: a randomized, double-blind, phase II trial (ANDES Study). Arthritis Rheumatol. 2020;72(9):1435-1446.

13. Montalban X, Arnold DL, Weber MS, et al. Placebo-controlled trial of an oral BTK inhibitor in multiple sclerosis. $N$ Engl J Med. 2019;380(25):2406-2417.

14. Haselmayer P, Camps M, Liu-Bujalski L, et al. Efficacy and pharmacodynamic modeling of the BTK inhibitor evobrutinib in autoimmune disease models. J Immunol. 2019;202(10):2888-2906

15. Jafarzadeh A, Chauhan P, Saha B, Jafarzadeh S, Nemati M. Contribution of monocytes and macrophages to the local tissue inflammation and cytokine storm in COVID-19: lessons from SARS and MERS, and potential therapeutic interventions. Life Sci. 2020; 257:118102.

16. Wiersinga WJ, Rhodes A, Cheng AC, Peacock SJ, Prescott HC. Pathophysiology, transmission, diagnosis, and treatment of coronavirus disease 2019 (COVID-19): a review. JAMA. 2020;324(8):782-793.

17. Mathew D, Giles JR, Baxter AE, et al. Deep immune profiling of COVID-19 patients reveals distinct immunotypes with therapeutic implications. Science. 2020;369(6508) eabc8511.

18. Woodruff MC, Ramonell RP, Nguyen DC, et al. Extrafollicular B cell responses correlate with neutralizing antibodies and morbidity in COVID-19. Nat Immunol. 2020;21(12):1506-1516.

19. Juno JA, Tan HX, Lee WS, et al. Humoral and circulating follicular helper T cell responses in recovered patients with COVID-19. Nat Med. 2020;26(9):1428-1434.

20. Tan AT, Linster M, Tan CW, et al. Early induction of functional SARS-CoV-2-specific $\mathrm{T}$ cells associates with rapid viral clearance and mild disease in COVID-19 patients. Cell Rep. 2021;34(6):108728.

21. Wang J, Jiang M, Chen X, Montaner LJ. Cytokine storm and leukocyte changes in mild versus severe SARS-CoV-2 infection: review of 3939 COVID-19 patients in China and emerging pathogenesis and therapy concepts. J Leukoc Biol. 2020;108(1): $17-41$.

22. Jafarzadeh A, Jafarzadeh S, Nozari P, Mokhtari P, Nemati M. Lymphopenia an important immunological abnormality in patients with COVID-19: possible mechanisms. Scand J Immunol. 2021;93(2):e12967.

23. Diao B, Wang C, Tan Y, et al. Reduction and functional exhaustion of $\mathrm{T}$ cells in patients with coronavirus disease 2019 (COVID-19). Front Immunol. 2020;11:827.

24. Mazzoni A, Salvati L, Maggi L, et al. Impaired immune cell cytotoxicity in severe COVID-19 is IL-6 dependent. J Clin Invest. 2020;130(9):4694-4703.

25. Sekine T, Perez-Potti A, Rivera-Ballesteros O, et al. Robust $\mathrm{T}$ cell immunity in convalescent individuals with asymptomatic or mild COVID-19. Cell. 2020;183(1): 158-168.e114.

26. Williamson EJ, Walker AJ, Bhaskaran K, et al. Factors associated with COVID-19 related death using OpenSAFELY. Nature. 2020;584(7821):430-436.

27. Bsteh G, Bitschnau C, Hegen H, et al. Multiple sclerosis and COVID-19: how many are at risk?. Eur J Neurol. 2020. doi: 10.1111/ene.14555.

28. Fan M, Qiu W, Bu B, et al. Risk of COVID-19 infection in MS and neuromyelitis optica spectrum disorders. Neurol Neuroimmunol Neuroinflamm. 2020;7(5):e787.

29. Schmidt ME, Varga SM. The CD8 T cell response to respiratory virus infections. Front Immunol. 2018;9:678.

30. Ochs HD, Smith CI. X-linked agammaglobulinemia. A clinical and molecular analysis. Medicine. 1996;75(6):287-299.

31. Lund FE, Randall TD. Effector and regulatory B cells: modulators of CD4+ T cell immunity. Nat Rev Immunol. 2010;10(4):236-247.

32. Corneth OBJ, Klein Wolterink RGJ, Hendriks RW. BTK signaling in B cell differentiation and autoimmunity. Curr Top Microbiol Immunol. 2016;393:67-105.
33. Seow J, Graham C, Merrick B, et al. Longitudinal observation and decline of neutralizing antibody responses in the three months following SARS-CoV-2 infection in humans. Nat Microbiol. 2020;5(12):1598-1607.

34. Zhao J, Yuan Q, Wang H, et al. Antibody responses to SARS-CoV-2 in patients with novel coronavirus disease 2019. Clin Infect Dis. 2020;71(16):2027-2034.

35. Alamri A, Fisk D, Upreti D, Kung SKP. A missing link: engagements of dendritic cells in the pathogenesis of SARS-CoV-2 infections. Int J Mol Sci. 2021;22(3):1118.

36. Banu N, Panikar SS, Leal LR, Leal AR. Protective role of ACE2 and its downregulation in SARS-CoV-2 infection leading to macrophage activation syndrome: therapeutic implications. Life Sci. 2020;256:117905.

37. Chong EA, Roeker LE, Shadman M, Davids MS, Schuster SJ, Mato AR. BTK inhibitors in cancer patients with COVID-19: "The winner will be the one who controls that chaos" (Napoleon Bonaparte). Clin Cancer Res. 2020;26(14):3514-3516.

38. Lee KG, Xu S, Kang ZH, et al. Bruton's tyrosine kinase phosphorylates Toll-like receptor 3 to initiate antiviral response. Proc Nat Acad Sci USA. 2012;109(15): 5791-5796.

39. van den Berg DF, Te Velde AA. Severe COVID-19: NLRP3 inflammasome dysregulated. Front Immunol. 2020;11:1580.

40. Weber ANR, Bittner Z, Liu X, Dang TM, Radsak MP, Brunner C. Bruton's tyrosine kinase: an emerging key player in innate immunity. Front Immunol. 2017;8:1454

41. Block H, Zarbock A. The role of the tec kinase Bruton's tyrosine kinase (Btk) in leukocyte recruitment. Int Rev Immunol. 2012;31(2):104-118.

42. Ye B, Zhou C, Guo H, Zheng M. Effects of BTK signalling in pathogenic microorganism infections. J Cell Mol Med. 2019;23(10):6522-6529.

43. Krupa A, Fol M, Rahman M, et al. Silencing Bruton's tyrosine kinase in alveolar neutrophils protects mice from LPS/immune complex-induced acute lung injury. Am J Physiol Lung Cell Mol Physiol. 2014;307(6):L435-L448.

44. Florence JM, Krupa A, Booshehri LM, Davis SA, Matthay MA, Kurdowska AK Inhibiting Bruton's tyrosine kinase rescues mice from lethal influenza-induced acute lung injury. Am J Physiol Lung Cell Mol Physiol. 2018;315(1):L52-L58.

45. Roschewski M, Lionakis MS, Sharman JP, et al. Inhibition of Bruton tyrosine kinase in patients with severe COVID-19. Sci Immunol. 2020;5(48):eabd0110.

46. AstraZeneca. Update on CALAVI phase II trials for Calquence in patients hospitalised with respiratory symptoms of COVID-19 [press release]. astrazeneca.com $/ \mathrm{media}$ centre/press-releases/2020/update-on-calavi-phase-ii-trials-for-calquence-in-patientshospitalised-with-respiratory-symptoms-of-covid-19.html (accessed April 13, 2021).

47. Quinti I, Lougaris V, Milito C, et al. A possible role for B cells in COVID-19? Lesson from patients with agammaglobulinemia. J Allergy Clin Immunol. 2020;146(1) 211-213.e214

48. Soresina A, Moratto D, Chiarini M, et al. Two X-linked agammaglobulinemia patients develop pneumonia as COVID-19 manifestation but recover. Pediatr Allergy Immunol. 2020;31(5):565-569.

49. Joyner MJ, Carter RE, Senefeld JW, et al. Convalescent plasma antibody levels and the risk of death from Covid-19. N Engl J Med. 2021;384(11):1015-1027.

50. Siegrist C-A. Vaccine immunology. In: Plotkin SA, Orenstein W, Offit PA, editors Vaccines, 6th ed. Elsevier, Inc.; 2013.

51. Jeyanathan M, Afkhami S, Smaill F, Miller MS, Lichty BD, Xing Z. Immunologica considerations for COVID-19 vaccine strategies. Nat Rev Immunol. 2020;20(10) 615-632.

52. Cameron MJ, Bermejo-Martin JF, Danesh A, Muller MP, Kelvin DJ. Human immunopathogenesis of severe acute respiratory syndrome (SARS). Virus Res. 2008; 133(1):13-19.

53. Jafarzadeh A, Nemati M, Saha B, Bansode YD, Jafarzadeh S. Protective potentials of type III interferons in COVID-19 patients: lessons from differential properties of type I- and III interferons. Viral Immunol. 2020;34(5):307-320.

54. Jackson LA, Anderson EJ, Rouphael NG, et al. An mRNA vaccine against SARS-CoV2-preliminary report. N Engl J Med. 2020;383(20):1920-1931.

55. MedRxiv. BNT162b2 induces SARS-CoV-2-neutralising antibodies and T cells in humans. medrxiv.org/content/10.1101/2020.12.09.20245175v1 (accessed April 13, 2020).

56. Sun C, Gao J, Couzens L, et al. Seasonal influenza vaccination in patients with chronic lymphocytic leukemia treated with ibrutinib. JAMA Oncol. 2016;2(12):1656-1657.

57. Douglas AP, Trubiano JA, Barr I, Leung V, Slavin MA, Tam CS. Ibrutinib may impair serological responses to influenza vaccination. Haematologica. 2017;102(10): e397-e399.

58. Andrick B, Alwhaibi A, DeRemer DL, et al. Lack of adequate pneumococcal vaccination response in chronic lymphocytic leukaemia patients receiving ibrutinib. $\mathrm{Br} J$ Haematol. 2018;182(5):712-714.

59. Pleyer C, Ali MA, Cohen JI, et al. Effect of Bruton tyrosine kinase inhibitor on efficacy of adjuvanted recombinant hepatitis B and zoster vaccines. Blood. 2021;137(2): 185-189.

60. Passalacqua DJ, Sleasman JW, Goodenow MM. Normal T cell response following tetanus immunization in X-linked agammaglobulinemia (XLA). Pediatr Res. 1999;45(12).

61. Liu Y, Wu Y, Lam KT, Lee PP, Tu W, Lau YL. Dendritic and T cell response to influenza is normal in the patients with $\mathrm{X}$-linked agammaglobulinemia. J Clin Immunol. 2012;32(3):421-429.

62. Luk ADW, Ni K, Wu Y, et al. Type I and III interferon productions are impaired in $\mathrm{X}$-Linked agammaglobulinemia patients toward poliovirus but not influenza virus. Front Immunol. 2018;9:1826.

63. Stuve O, Bennett JL, Hemmer B, et al. Pharmacological treatment of early multiple sclerosis. Drugs. 2008;68(1):73-83. 


\title{
Neurology \\ Neuroimmunology \& Neuroinflammation
}

\author{
Balancing Potential Benefits and Risks of Bruton Tyrosine Kinase Inhibitor Therapies \\ in Multiple Sclerosis During the COVID-19 Pandemic \\ Martin S. Weber, Jacqueline A. Nicholas and Michael R. Yeaman \\ Neurol Neuroimmunol Neuroinflamm 2021;8; \\ DOI 10.1212/NXI.0000000000001067
}

This information is current as of September 8, 2021

\begin{tabular}{|c|}
\hline $\begin{array}{l}\text { Updated Information \& } \\
\text { Services }\end{array}$ \\
\hline References \\
\hline Subspecialty Collections \\
\hline Permissions \& Licensing \\
\hline Reprints \\
\hline
\end{tabular}

Updated Information \& including high resolution figures, can be found at:

http://nn.neurology.org/content/8/6/e1067.full.html

This article cites 58 articles, 7 of which you can access for free at: http://nn.neurology.org/content/8/6/e1067.full.html\#\#ref-list-1

This article, along with others on similar topics, appears in the following collection(s):

COVID-19

http://nn.neurology.org//cgi/collection/covid_19

Multiple sclerosis

http://nn.neurology.org//cgi/collection/multiple_sclerosis

Information about reproducing this article in parts (figures,tables) or in its entirety can be found online at:

http://nn.neurology.org/misc/about.xhtml\#permissions

Information about ordering reprints can be found online:

http://nn.neurology.org/misc/addir.xhtml\#reprintsus

Neurol Neuroimmunol Neuroinflamm is an official journal of the American Academy of Neurology.

Published since April 2014, it is an open-access, online-only, continuous publication journal. Copyright

Copyright (C) 2021 The Author(s). Published by Wolters Kluwer Health, Inc. on behalf of the American

Academy of Neurology.. All rights reserved. Online ISSN: 2332-7812.

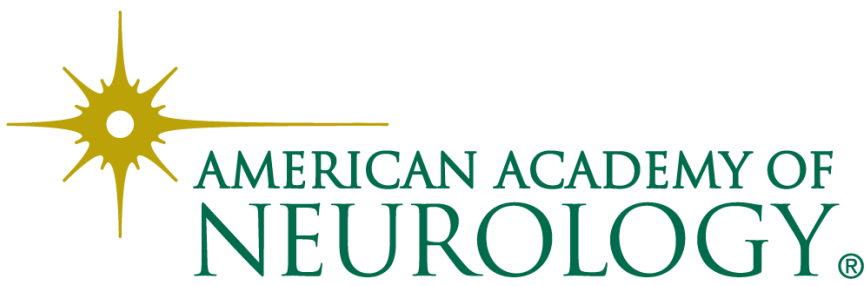

